


\section{De la unidad a lo común: hacia una articulación feminista de las diferencias. La experiencia de la Plataforma de la Marcha Mundial de Mujeres de Euskal Herria ${ }^{1}$}

\section{Itziar Gandarias Goikoetxea ${ }^{2}$ \\ Universidad Autónoma de Barcelona; Universidad de Deusto, España itzi.gandarias@gmail.com; itziar.gandarias@deusto.es

\footnotetext{
Este artículo es fruto de una investigación de tesis en el marco del Programa de Doctorado Persona y Sociedad en el mundo contemporáneo del Departamento de Psicología Social de la Universitat Autònoma de Barcelona. No contó con financiación.

2 Máster en Investigación en Psicología Social, Universitat Autònoma de Barcelona. Estudiante del Programa de Doctorado en Psicología Social, Universitat Autònoma de Barcelona (España). Profesora, Departamento de Psicología Social y Desarrollo, Universidad de Deusto en Bilbao (España).
} 


\title{
De la unidad a lo común: hacia una articulación feminista de las diferencias. La experiencia de la Plataforma de la Marcha Mundial de Mujeres de Euskal Herria
}

\section{Resumen}

El presente texto explora, desde una metodología feminista y activista, el proceso de articulación de organizaciones de mujeres migradas y feministas locales dentro de la Plataforma de la Marcha Mundial de Mujeres de Euskal Herria. Con base en fragmentos del diario de campo, documentos colectivos de la Plataforma y mi propia experiencia como activista dentro de la misma, analizo las prácticas que se están llevando a cabo entre los diferentes colectivos para tejer alianzas. Estas prácticas, que no quedan exentas de nudos ni dificultades, como tampoco de continuidades que reproducen las lógicas de la herencia colonial y patriarcal entre las propias mujeres, reconfiguran la noción de diferencia y se aproximan a lo que algunas autoras vienen denominando la política de lo común.

Palabras clave: diferencia; feminismos; mujeres migradas; articulación; común

\section{From Unity to the Common: Towards a Feminist Articulation of Differences. The Experience of the Platform for the World March of Women of Euskal Herria}

\begin{abstract}
This paper explores, using a feminist and activist methodology, the articulation experience of local feminist and migrated women organizations within the Platform for the World March of Women of Euskal Herria. Based on field diary fragments, collective documents of the Platform, and my own experience as an activist within the Platform, I analyze the practices that are taking place between the various collectives to forge alliances. These practices, with their own obstacles and difficulties, as well as continuities that reproduce the colonial and patriarchal rationale among women themselves, have reconfigured the notion of difference and are close to what some authors are calling the politics of the common.
\end{abstract}

Keywords: difference; feminisms; immigrant women; articulation; the common

\section{Da unidade ao comum: Para uma articulação feminista das diferenças. Experiência da Plataforma da Marcha Mundial das Mulheres de Euskal Herria}

\section{Resumo}

O presente texto explora, desde uma metodologia feminista e ativista, a experiência de articulação de organizações das mulheres migrantes e feministas locais dentro da Plataforma da Marcha Mundial de Mulheres de Euskal Herria. Baseados em fragmentos do diário de campo, documentos coletivos da Plataforma e a minha própria experiência como ativista no âmbito da Plataforma, analiso as práticas que estão ocorrendo entre os diferentes coletivos para tecer parcerias. Essas práticas que nem são isentas de nós ou dificuldades, nem de continuidades reproduzindo a lógica da herança colonial e patriarcal entre as próprias mulheres, reconfiguram a noção de diferença e se aproximam do que algumas autoras vêm chamar de a politica do comum.

Palavras-chave: diferença; feminismos; mulheres migrantes; articulação; comum 


\section{Introducción}

El feminismo, más que un movimiento unificado, es un campo discursivo de acción, amplio y heterogéneo, marcado desde sus inicios por el cuestionamiento, la tensión y la disidencia (Álvarez, 1998). Si algo ha caracterizado a las diferentes propuestas del feminismo, es su voluntad interrogadora frente a las categorias que uniformizan la realidad (Fuss, 2013), no solo cuestionando la configuración de un sujeto de dominación externo, sino también al interior de la propia categoría de género (Davis, 1981; Hooks, 1981; Moraga y Anzaldúa, 1981; Lorde, 1984). Este repensar de modo continuo la conformación del sujeto mujer es, según algunas autoras (Braidotti, 1992; Butler, 2001), lo que dota al feminismo de herramientas para, precisamente, no enquistarse ni cerrarse, y poder estar abiertas a la autorreflexión y a la construcción permanente. Como sostiene Rosi Braidotti (1992) debemos tener el coraje de hacer frente a nuestras diferencias, porque cuestionar críticamente "las diferencias entre las mismas mujeres" no destruye la política feminista, sino que la complejiza y la enriquece tanto en la teoría como en la práctica.

Por tanto, uno de los desafios actuales es cómo entender ahora las diferencias, perdida la cohesión que brindaba el paraguas del sujeto mujer universal (Femenías, 2011) y cómo articular las diferencias para habilitar acciones contrahegemónicas (Fraser, 2008) que resignifiquen la política. Tal y como advierte Butler (2001), el dilema está en construir un proyecto feminista, un nosotras, a través de factores comunes, pero teniendo en cuenta la construcción fabricada de la categoría de género y por lo tanto la complejidad y variabilidad de identidades que contiene. Así, el reto de construir "solidaridades" y "alianzas" entre mujeres con distintas experiencias y necesidades "es mucho más dificil que el asumir que todas compartimos la misma opresión y por lo tanto coincidimos con una agenda política establecida por unas pocas desde un espacio de poder" (Hernández Castillo, 2003, p. 118).

Desde diferentes geografias y contextos, algunas autoras en el marco de los feminismos transnacionales (Grewal and Kaplan, 1994; Mendoza, 2002; Mohanty, 2003) defienden la posibilidad de hacer una 
política solidaria feminista atravesada por la clase, la raza, la sexualidad y las fronteras nacionales, donde la yuxtaposición de los diferentes intereses de las mujeres sea el punto transversal y de arranque para la configuración de alianzas. Otras autoras, desde las propuestas de los feminismos descoloniales, cuestionan el privilegio de la solidaridad de las mujeres blancas (Bouteldja, 2010) y son críticas frente a cómo a pesar del reconocimiento de la necesidad de un análisis imbricado de raza/clase/género/(hetero)sexualidad, la categoría de género sigue siendo el epicentro en la mayoría de los análisis feministas (Espinosa, 2014). En este sentido, María Lugones (2008), a través de la colonialidad del género, critica el etnocentrismo inmerso en la categoria de género, ya que fue construida para corresponder solo a lo humano, es decir, a los seres de razón cuyo origen es blanco y europeo.

Extrapolando estos debates, al actual contexto de crisis multidimensional y civilizatoria (Pérez Orozco, 2012), el auge del racismo y la violencia contra las mujeres en Europa, hace inminente la necesidad de políticas de articulación entre organizaciones de mujeres y feministas, tanto migrantes como autóctonas, que no reproduzcan las relaciones coloniales y patriarcales.

Por ello, en el presente texto se explora, a través de una metodología feminista y activista, la experiencia de articulación de la Plataforma de la Marcha Mundial de Mujeres de Euskal Herria ${ }^{3}$ que, desde hace dos años, reúne a mujeres migradas y autóctonas y de la que la autora también es parte. En base a fragmentos del diario de campo, documentos colectivos de la Plataforma y mi propia experiencia como activista dentro de una de las organizaciones de la Plataforma, Mujeres del Mundo $\mathrm{Babel}^{4}$, conformada por mujeres migradas y locales, analizo las prácticas de ruptura y experiencias de novedad que están posibilitando tejer acciones colectivas no solo desde los intereses comunes,

Es relevante distinguir Euskal Herria de la Comunidad Autónoma Vasca, conformada por las provincias Gipuzkoa, Bizkaia y Araba. Euskal Herria es la nación donde se encuentran los siete territorios históricos (Araba, Bizkaia, Gipuzkoa, Nafarroa Garaia, Behenafarroa, Lapurdi y Zuberoa) que conforman el pueblo vasco. Es el país del euskera y de la cultura vasca, donde sus habitantes comparten una identidad que aspira a recuperar su derecho a constituirse como Estado independiente y soberano, superando la histórica dominación de los viejos Estados español y francés.

4 El colectivo Mujeres del Mundo Babel es una organización de mujeres que fomenta el empoderamiento y el encuentro afectivo de mujeres con trayectoria personal, social y cultural diferente. Más información disponible en: http://www. mujeresdelmundobabel.org 
sino también poniendo en el centro las desigualdades entre las propias participantes de la plataforma.

Comienzo el texto abordando el dilema de la diferencia dentro de la teoría feminista y la noción de la política de lo común como propuesta para la articulación de diferencias. En segundo lugar, presento la Marcha Mundial de Mujeres, sus orígenes, características y su proceso de constitución en el País Vasco. A continuación, analizo cuatro prácticas significativas rescatadas de la experiencia de la Plataforma de la Marcha Mundial en Euskal Herria, para finalizar con algunas consideraciones acerca de cómo tejer articulaciones feministas plurales y diversas.

\section{El dilema de la diferencia y la política de lo común}

Hoy en día dentro del movimiento feminista está ampliamente aceptado que la mujer no es una categoria unitaria, sin embargo, permanece la cuestión de si puede ser una categoría unificadora (Brah, 1996/2011). Para esta autora, el signo mujer "tiene su propia especificidad constituida dentro y a través de configuraciones históricamente específicas de relaciones de género" (Brah, 1996/2011, p. 131). Por eso, a la hora de pensar en alianzas necesitamos examinar las formas en las que esas especificidades de "ser mujer" están construidas de forma similar y diferente dentro de las relaciones de poder patriarcales, raciales y de clase. Esto implica partir de que las identidades son relaciones, es decir, "se producen a través de la diferencia y no al margen de ella” (Restrepo, 2006, p. 25). Desde esta mirada relacional, la diferencia se constituye y se organiza en relaciones sistémicas por medio de discursos económicos, culturales y políticos y prácticas institucionales, a través de lo que Avtar Brah (1996/2011, p. 146) denomina "la sistematicidad de las contingencias". Es decir, la diferencia se construye mediante la articulación, históricamente variable, de los micro y macroregímenes de poder, en los cuales las formas de diferenciación como la raza, el género, la clase o la edad se constituyen como formaciones estructuradas. 
Así, las identidades, siguiendo a Stuart Hall (2003), "emergen en el juego de modalidades específicas de poder y, por ello, son más un producto de la marcación de la diferencia y la exclusión que signo de una unidad idéntica y naturalmente constituida" (p. 18). De ahí que identidad y diferencia deban pensarse como procesos mutuamente constitutivos.

Por otro lado, las relaciones sociales se constituyen y actúan en todos los espacios de una formación social, incluida la cotidianidad. De esta manera, la diferencia sería una articulación entre subjetividad y estructura, donde las identidades nunca son fijas, ni singulares, sino más bien "una multiplicidad de relaciones en constante transformación” (Brah, 1996/2011, p. 131).

Avtar Brah (1996) plantea dos significados para dar cuenta de la diferencia. Por un lado, "diferencia" como marca de diferenciación de nuestras historias colectivas y, en segundo lugar, "diferencia" como experiencia personal codificada en la biografia personal de cada individuo.

Aunque ambas perspectivas se entrecruzan no tienen por qué tener una correspondencia directa. Como señala la autora: "Podemos experimentar la subordinación sin reconocerla necesariamente como tal. La misma práctica social puede asociarse con distintos significados en diferentes contextos culturales. Puede existir una disyunción psíquica y emocional entre cómo nos sentimos acerca de algo y cómo creemos que deberíamos sentirnos desde el punto de vista de nuestra perspectiva analítica y política" (Brah, 1996/2011, p. 116).

Siguiendo a la autora, se trata de establecer las diferencias entre las mujeres migrantes y las autóctonas, por un lado, como categorías marcadas dentro de procesos históricos específicos de clase, racismo, colonialismo, migración, etc. y, por otro, las mujeres migrantes $\mathrm{y}$ autóctonas como individuos con biografias y experiencias vitales concretas. Mientras que la primera hace referencia a divisiones y estructuras sociales, la segunda hace hincapié en las prácticas diarias de las mujeres y conceptualiza a la persona como un sujeto complejo 
y continuamente cambiante, en el que pueden tener lugar múltiples contradicciones y cuyas prácticas diarias pueden reforzar, pero también minar, las divisiones sociales.

De esta manera, tal y como sugiere Minow, necesitamos una nueva forma de pensar la diferencia que implique el rechazo de la idea de que igualdad versus diferencia es realmente una oposición. Para este autor, "tanto el foco puesto en la diferencia como en la indiferencia total hacia ella hacen que se corra el riesgo de recrearla" (1985, p. 196).

Como podemos ver, las nociones de identidad y diferencia siguen siendo pivotes fundamentales en las reflexiones teóricas feministas. En ese sentido, las preguntas que surgen son: ¿cómo tejer hoy en día articulaciones políticas sin caer en el juego recursivo de las identidades o la redundancia de las diferencias? ¿Cómo articulamos singularidad y vida en común?

En los últimos años, algunas autoras vienen teorizando sobre lo que se ha denominado la política de lo común (Garcés, 2013; Gil, 2014, 2015). Para Silvia L. Gil (2015), vida común puede entenderse como una adición de identidades o realidades preexistentes que se articulan para una alianza puntual. En este caso, como sostiene la autora, "al partir de sustancias predefinidas, la posibilidad de transformación subjetiva es menor, así como mayor el riesgo de construir una comunidad cerrada sobre sî" $(2015$, p. 4). Pero lo común también puede ser un proceso en el que al entrar en contacto con la otra se consigue ser transformada y afectada. De este proceso no salimos igual, "dejamos de ser lo que éramos y llegamos a ser algo que no nos esperábamos" (p. 4). En este caso, como diría Marina Garcés (2013), no hablamos de un sujeto plural conformado por una suma de "yoes", porque "del yo al nosotros no hay una suma, sino una operación de coimplicación" (p. 49). Esta segunda perspectiva conlleva un acto de generosidad politica (Gil, 2015, p. 4), en el que lo más importante no es mantener fija una identidad previa, sino todo lo contrario; la clave radicaría en estar abiertas a la relación con lo diferente que nos constituye. Esto enlaza con la noción de interdependencia de Butler (2009), que implica ser conscientes de que no somos personas aisladas sino 
insertas en un entramado de vínculos y relaciones que nos preceden y que producimos a través de nuestra cotidianidad. Es por ello que, como señala Butler, "nuestra supervivencia dependerá no de la vigilancia y defensa de una frontera, sino de reconocer nuestra estrecha relación con los demás" (2009, p. 82).

\section{La Marcha Mundial de Mujeres: un movimiento en construcción}

La Marcha Mundial de las Mujeres (en adelante MMM), es un movimiento mundial de acciones feministas que reúne grupos de mujeres y organizaciones que actúan para eliminar las causas que originan la pobreza y la violencia contra las mujeres. Desde el año 2000 ha movilizado, a través de acciones internacionales, nacionales y regionales, a centenares de mujeres en torno a la lucha contra todas las formas de desigualdades y discriminaciones sufridas.

Sus valores y acciones apuntan hacia un cambio social, económico y político y se articulan en torno a la globalización de las solidaridades, de la igualdad entre los hombres y las mujeres, entre las propias mujeres y entre los pueblos, el respeto y el reconocimiento de la diversidad entre las mujeres, la multiplicidad de estrategias, la valorización del liderazgo de las mujeres y la fuerza de las alianzas entre mujeres y con otros movimientos sociales internacionalistas.

La idea de organizar la primera MMM, en el año 2000, surge como consecuencia de una iniciativa del movimiento de mujeres de Quebec, cuando en 1995 celebró una marcha contra la pobreza que reunió a más de 850 mujeres. Durante los 10 dias que duró la movilización, 15.000 personas se adhirieron, consiguiendo una gran repercusión a nivel internacional. Como señala Sara de Roure (2010), "más que la simple constatación de las desigualdades y la necesidad de permitir el acceso al poder, lo que el feminismo planteaba iba más allá. La principal razón para marchar en aquel momento era aumentar el alcance 
y el impacto de sus análisis, reivindicando un cambio profundo en las reglas políticas, sociales y económicas" (p. 2).

La participación en aquella marcha de unas veinte mujeres de los países del Sur, evidenció la emergente necesidad de mundializar las solidaridades. Por ello, en el año 2000 se realiza un primer llamamiento de una MMM con el lema "2.000 razones para marchar contra la pobreza y la violencia sexista", que inició el 8 de marzo en Quebec y Ginebra y finalizó el 17 de octubre, Día Internacional para la eliminación de la pobreza en el palacio de Naciones Unidas en Nueva York. La marcha encontró mucho apoyo de distintos sectores de mujeres, lo que además de ir constituyendo el movimiento instauró la realización de acciones mundiales cada cinco años. Para ello, fue clave, como señala de Roure (2010), el método de construcción y articulación que buscaba reunir mujeres de bases a través de un amplio proceso de movilización y educación popular. La MMM incorporó como parte de su política de movimiento la reivindicación de que las mujeres son sujetos activos en los procesos de cambio del modelo patriarcal, racista, homofóbico y depredador del medio ambiente. Tras la IV Conferencia internacional de mujeres de Beijing en 1995, la MMM era una propuesta de movilización diferente, tanto por su método de organización como por su agenda transformadora (Faria, 2005).

Después del éxito de la primera acción tuvo lugar un proceso de debate en numerosos países para consensuar la "Carta de las mujeres para la humanidad", que se aprobó en diciembre del 2004 en El Congo. Ese año, la MMM inició en Nueva York y hasta su fin, el 17 de octubre, pasó como testigo la Carta, país por país. La III Acción Internacional, en el año 2010, se inició con el Centenario de la Declaración Internacional del Día de las Mujeres y terminó en El Congo con una denuncia contundente sobre la violencia que se ejerce contra las mujeres en los contextos de guerra.

El pasado año, en 2015, se celebró la IV Acción Internacional. En Europa la Acción consistió en una caravana feminista que partió de Kurdistán el 8 de marzo y culminó en Lisboa el 17 de octubre, cuyo 
lema fue "Nuestros Cuerpos, nuestros territorios. Seguiremos en marcha hasta que todas seamos libres".

Actualmente, la Marcha está organizada en más de 70 países y funciona gracias a la participación activa de las coordinaciones nacionales, el Comité Internacional - compuesto por representantes de las regiones- y un secretariado internacional que actualmente se encuentra en Mozambique. En la dinámica de funcionamiento, los grupos son reconocidos independientemente de que tengan o no legalidad a nivel oficial. Es el caso de Quebec, Cataluña, Galicia o del País Vasco, que tienen delegación propia.

\section{La Plataforma de la Marcha Mundial en Euskal Herria}

La Plataforma de la Marcha Mundial de Euskal Herria ${ }^{5}$ (en adelante MME) aglutina a diferentes organizaciones feministas, de mujeres y sindicatos desde el año 2000. En esa primera acción internacional se realizaron diversas actividades en diferentes pueblos, al tiempo que se presentaron mociones en los ayuntamientos para conseguir adhesiones y se organizó una marcha a Bruselas para apoyar la movilización europea. La segunda movilización del 2005 tuvo una gran repercusión; un autobús morado recorrió pueblos y capitales. También se planteó un debate de la Carta de las Mujeres, recogiendo los aportes de los diferentes pueblos y grupos feministas, y en el 2007 se presentó la Carta de las Mujeres para Euskal Herria. La participación e impacto en la III Acción Internacional fue más modesta ${ }^{6}$, pero se decidió continuar apostando por la Plataforma, para también denunciar situaciones locales que afectaban a las mujeres que viven en Euskal Herria.

Una de las reflexiones comunes que los grupos de mujeres feministas vascas reconocian en la primera exploración que hicimos al inicio de la

\footnotetext{
Puede verse más información sobre la Plataforma de la Marcha Mundial de Euskal Herria en la siguiente web: http:// www.emakumeenmundumartxa.eus

6 Para más información sobre la III Acción: http://2010emakumeenmundumartxa.blogspot.com.es
} 
tesis era el vacío de la MME respecto a la escasa participación de mujeres migradas (Gandarias y Pujol, 2013). Más tarde, en un encuentro con las cinco organizaciones que participaron en la primera fase de la tesis, volvió a resonar la necesidad de crear espacios comunes de articulación y como consecuencia de ello, en noviembre del 2013, se convoca una asamblea abierta de la MME a la que se invita a nuevos grupos feministas y de mujeres ${ }^{7}$.

Durante los siguientes dos años, en asambleas cada tres meses, además de ir definiendo conjuntamente el funcionamiento y la organización, se replantean los cuatro temas o campos de acción ${ }^{8}$ que se ajustan a la mayor diversidad de grupos de la MME: violencias transistémicas, cuerpos y sexualidades, sostenibilidad de la vida y trabajo en red y gestión de la diversidad.

Este proceso de apertura ha dado sus frutos. La caravana feminista a su paso por Euskal Herria recorrió 27 pueblos durante una semana y más de 200 mujeres fuimos al cierre de la caravana europea en Lisboa el 17 de octubre. Esta caravana ha sido un disparador para fortalecer a los grupos feministas que ya existían, pero sobre todo ha permitido articular el movimiento feminista en lugares donde no estaba activado, lo que ha dado lugar al surgimiento de nuevos grupos.

\section{Hacia una construcción de lo común a través de las diferencias y las desigualdades}

Tomando los debates más arriba desarrollados sobre las nociones de diferencia y la política de lo común, presentamos a continuación un análisis del proceso de articulación de la Plataforma de la MME, haciendo énfasis tanto en las prácticas de ruptura y experiencia de novedad como en la reproducción de lógicas patriarcales-coloniales entre las participantes.

Producto de esa apertura, el colectivo transfeminista Medeak — https://medeak.wordpress.com—y Mujeres del Mundo Babel comienzan a participar activamente en la Plataforma.

8 Se puede ver el desarrollo de estos cuatro campos de acción en el dosier de comunicación: http://emakumeenmundumartxa. eus/fitxategiak/media/2015/1df3e443ab31bf1dec8ee8f971c32342dossier-castpdf.pdf 
El análisis da cuenta de una investigación activista feminista (Biglia, 2007) que la autora ha realizado del proceso durante dos años: desde el 2013 hasta el 2015, tras participar en las asambleas abiertas y también en el grupo dinamizador ${ }^{9}$ como portavoz de uno de los grupos nuevos que se incorporó a la Plataforma: el colectivo Mujeres del Mundo Babel. Este colectivo, además, ha sido canal para que otras mujeres migradas pudieran participar en la MME y para situar en la agenda de la Plataforma temas tan urgentes y emergentes como el racismo, la islamofobia o las nuevas formas de colonialismo.

Con base en al análisis de documentos colectivos y los registros del diario de campo, he identificado cuatro prácticas significativas: 1) La presencia y participación activa de las mujeres migradas; 2) La transgresión de la retórica de las diferencias; 3) La política de acordar los desacuerdos; y, por último, 4) Tejer espacios emocionales de cuidado entre nosotras.

\section{La presencia y participación activa: "O nos mostramos o no existimos"}

Una de las reflexiones de los últimos años en Mujeres del Mundo, que impulsó a participar activamente dentro de la MME, fue "O nos mostramos o no existimos". La plataforma de la MME era un espacio que llevaba tiempo funcionando; aunque se había hecho una llamada a grupos nuevos para que entraran, era necesario atreverse a "cruzar la puerta", para unirse a una plataforma que ya estaba conformada y tenía sus propias dinámicas. Mujeres del Mundo es consciente de ese salto cualitativo que supone salir de tu espacio e ir al encuentro de las otras desde una presencia activa. No fue una apuesta tímida, sino una decisión política colectiva para llevar a esos espacios discursos elaborados que visibilizaran las reivindicaciones de las mujeres migradas. Como manifestaba una compañera de la organización

\footnotetext{
9 Las decisiones de la Plataforma de la Marcha Mundial de Mujeres se toman en las asambleas abiertas. El grupo dinamizador, conformado por 5-6 personas representantes de algunas de las organizaciones, es el encargado del trabajo más operativo: coordinar las reuniones, preparar asambleas, coordinarse con Europa, etc. Actualmente en el grupo dinamizador participamos representantes de organizaciones de mujeres feministas vascas, sindicatos, transfeministas y mujeres migradas.
} 
Mujeres del Mundo: "No solo es cuestión de ir a los espacios y hacer acto de presencia, sino llevar un discurso construido en torno a los temas que nos interesen y que nadie los va a sacar si no somos nosotras; una reflexión que nos permita reivindicar nuestros derechos y también nuestras necesidades" (Diario de campo, comunicación personal, 8 de abril del 2015).

De esta manera, se consideró imprescindible fortalecer el espacio interno del grupo con la finalidad de generar discursos y reflexiones colectivas, para luego trasladarlos a las asambleas generales de la $\mathrm{MME}^{10}$. Tomando la metáfora de virginia woolf $(1929 / 1995)$, la propuesta es generar espacios compartidos de articulación, pero sin abandonar el propio cuarto de cada grupo; estrategias que, aunque parezcan enfrentarse, no son contradictorias entre sí. se trata, como afirma obioma nnaemeka, de constituir estos espacios propios no como un fin, sino como un medio: "no nos debemos encerrar en un espacio cuyo confort puede ser letárgico [...] nuestra habilidad para usar nuestro espacio como una herramienta para remodelarnos a nosotras mismas y a la sociedad dependerá de nuestra voluntad de abrir las puertas de nuestro espacio para permitirle proyectarse e intersectarse con otros espacios" (2008, pp.162-163).

\section{Más allá de la retórica de las diferencias}

La participación de las mujeres migradas en la MME ha sido muy relevante para incidir no solo en la necesidad de dar cuenta de las diferencias en relación al origen, la clase, el estatus legal, la movilidad, la identidad sexual etc., sino para visibilizar y poner sobre la mesa los efectos político-materiales que esas marcas de diferenciación (Anthias, 2002) tienen en la vida cotidiana de las mujeres.

\footnotetext{
10 Para la participación en la Plataforma de la MME, se creó una comisión interna dentro de Mujeres del Mundo en la que participamos entre cinco y seis que nos reuníamos antes de las asambleas generales de la MME a prepararlas. Otro ejemplo de esta práctica es el que se ha llevado a cabo desde el colectivo Brujas y Diversas. El colectivo fue creado para apoyar la participación de Mujeres del Mundo dentro del proceso de construcción de la carta social de derechos en Euskal Herria, que reunió a diversidad de agentes y movimientos sociales. Más información en: http:// www.eskubidesozialenkarta.com/es
} 
Esta voluntad de ir más allá de numerar y describir las diferencias supone cuestionar las desigualdades que nos atraviesan y ser conscientes de que no todas tenemos las mismas condiciones de acceso a derechos y oportunidades sociales. Esto quedó muy bien reflejado en la explicación del eje de acción sobre diversidades que se diseñó para el dosier de comunicación. Cada uno de los cuatro campos de acción fue definido por un grupo diferente. Esto permitió que cada grupo pudiera reflejar sus luchas y reivindicaciones particulares. De esta manera, la responsabilidad de definir y reflexionar en torno al eje de diversidad y trabajo en red cayó en las organizaciones de mujeres migradas: "Somos mujeres provenientes de geografias distintas, con experiencias, recorridos, saberes, capacidades, identidades, formas de lucha y reivindicaciones diferentes que queremos defender, valorar y reconocer sin establecer jerarquías. Nos reconocemos diversas y a su vez desiguales en condiciones de derechos [...]" (Dosier de comunicación, Plataforma de la Marcha Mundial de Mujeres de Euskal Herria, 2015, el énfasis es mío).

Por tanto, el reto es no solo reconocer que somos diferentes (lesbianas, migrantes, precarias, transexuales, euskaldunes ${ }^{11}$ ), sino también reconocer que esas diferencias operan de manera muy distinta en cada una de nosotras, configurando experiencias de vida y de desigualdad concretas. Por ejemplo, para muchas mujeres migradas y autóctonas trabajadoras la participación en las reuniones de la marcha entre semana puede ser un impedimento (en el caso de las mujeres migradas que trabajan como empleadas del hogar en régimen interno esto se agudiza aun más, dadas sus largas jornadas laborales, que incluyen los fines de semana), algo que no resulta así para las mujeres que trabajan como liberadas ${ }^{12}$ de sus organizaciones, ya que las asambleas hacen parte de su empleo. Por otro lado, algunas mujeres vascas cuyo idioma materno y cotidiano es el euskera, un idioma subordinado frente a la hegemonía del castellano, presentan dificultades para expresarse y manejarse en castellano en las asambleas. Estas situaciones y experiencias concretas han sido claves para darnos cuenta de

11 Euskaldun: persona que en su vida cotidiana se comunica mayoritariamente en euskera.

12 Liberadas: personas pertenecientes a organizaciones sociales sindicales que trabajan para la organización y reciben un salario por ello. En muchas organizaciones la figura de la persona liberada suele ser temporal y rotativa por diferentes personas de la organización. 
que llevar a la práctica la diversidad, requiere pensar previamente en medios y mecanismos que la garanticen. Es muy fácil y bonito hablar en nuestros discursos del respeto a las diversas culturas políticas o a los diferentes ritmos y formas de funcionamiento de los grupos; sin embargo, asegurarlo en la práctica no es tan sencillo ni siempre posible. De ahí la importancia de ser conscientes y de dialogar sobre las limitaciones materiales que muchas veces tenemos en la práctica y desde ahí buscar alternativas.

En nuestro caso, una experiencia de aprendizaje ha sido la participación en las asambleas de mujeres con discapacidad física $\mathrm{y} / \mathrm{u}$ orgánica de la organización Fekoor ${ }^{13}$ de Bizkaia. Siempre las invitábamos con mucho entusiasmo, pero no teníamos en cuenta si el lugar donde se iba a realizar la asamblea era accesible. Algo similar nos ha ocurrido en relación a garantizar que mujeres migradas y autóctonas con hijos/as a su cargo pudieran venir a las asambleas, asegurándoles un sistema de guardería. Otro ejemplo ha sido la toma de decisiones en torno a cuándo hacer las reuniones, en qué horarios y qué dias de la semana o, en lo que respecta al idioma, garantizar que todas las mujeres pudieran entender la asamblea y también expresarse en la lengua en la que se sintieran más cómodas. Un mecanismo que utilizamos para ello, que viene implementándose en otros espacios de articulación de movimientos sociales ${ }^{14}$, es organizar grupos de traducción para las personas que no saben euskera; también que la persona que hace de traductora vaya rotando y, por otro lado, enviar todas las actas de las asambleas y los mensajes por correo electrónico en los dos idiomas: tanto castellano como euskera. Estas prácticas que parecen pequeñeces e insignificantes y que hablan más del "cómo" nos articulamos más que del "qué" hacemos juntos, requieren de un trabajo previo y de recursos de los que no siempre disponemos. Tal y como advierte Audre Lorde (1982) "estar juntas las mujeres no era suficiente. Éramos diferentes. [...] cada una tenía sus propias necesidades". De la misma manera, en la Marcha nos hemos dado cuenta de que simplemente estar juntas no basta y que es indispensable

\footnotetext{
13 Para más información sobre la federación de personas con discapacidad física y/u orgánica: http://www.fekoor.com

${ }^{14}$ En la plataforma que se creó para la construcción de la Carta de los Derechos Sociales de Euskal Herria se utilizó el mismo mecanismo para la traducción: http://www.eskubidesozialenkarta.com/es
} 
dedicar tiempo, esfuerzo y creatividad para generar mecanismos y recursos que combatan y no repitan las discriminaciones y prácticas de desigualdad existentes en la vida cotidiana.

Por tanto, transgredir la retórica de las diferencias significa ir más allá de la identificación y enumeración de las diferencias, visibilizando las desigualdades materiales que existen entre nosotras y que generan diferentes posiciones de poder y privilegio.

Poner en el centro esas desigualdades existentes entre nosotras desde la responsabilidad y no desde la culpa es ya en sí una práctica transformadora, porque la culpa no genera acción sino más bien inmovilismo; en cambio la responsabilidad es creativa y posibilitadora de agencia.

En este sentido, se torna fundamental que las mujeres vascas reconozcamos y asumamos nuestra posición de privilegio frente a las mujeres migradas, lo cual no elimina nuestra posición de subordinadas frente a otros sistemas de dominación. Las posiciones tanto normativas como periféricas no son siempre estables ni fijas. Por tanto, de acuerdo a Jennifer Nash (2008), el reto es analizar las formas en que privilegio y opresión pueden estar operando simultáneamente, lo que sin duda alguna rompe con la retórica sumatoria de las diferencias y sobre todo con la lógica dicotómica oprimida/opresora, norte/sur, mujer migrada/autóctona, etc.

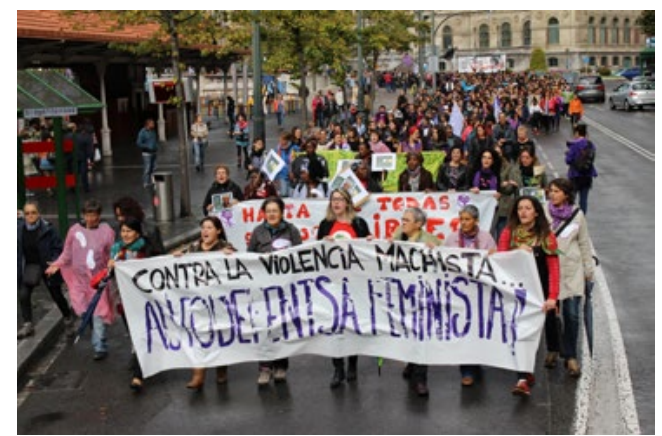

Figura 1. Manifestación realizada dentro del acto final de la Caravana Feminista en Bilbao el 4 de octubre de 2015

Foto: Ecuador Etxea 


\section{La politica de acordar los desacuerdos}

Una práctica innovadora que surgió en una de las asambleas -y que es un buen horizonte a tener presente, aunque nos cuesta integrarlo en nuestro funcionamiento precisamente porque es una práctica nueva y nos exige salir de la comodidad de nuestros modos de funcionamiento habituales-, ha sido no solo centrarnos en los temas que nos unen, los cuales son importantes y prioritarios de trabajar, sino también comenzar a dialogar y a poner en el centro de nuestros debates esos supuestos desacuerdos que nos separan y que sentimos que son infranqueables. En relación a esto, la metáfora que surgió en una de las asambleas fue la propuesta de "acordar los desacuerdos": “¿Por qué no perder el miedo a hablar de lo que nos separa? Quizás al hablarlo nos demos cuenta de que no es tanta la distancia entre nuestras posturas o sí... pero hablar y exponer nuestros puntos de vista y escucharnos, siempre nos va a llevar a acercarnos entre nosotras, aunque tengamos posturas diferentes" (Diario de campo, comunicación personal, 10 de mayo de 2014).

Acordar los desacuerdos es una metáfora de articulación que no pretende resolver las diferencias entre nosotras, sino todo lo contrario, aboga por la politica del diálogo para poder hablar y expresarlas, permitiéndonos acercarnos a la otra no porque estemos de acuerdo con su postura, sino porque nos reconocemos y nos respetamos mutuamente en nuestras diferencias. Poder escuchar y compartir nuestros desacuerdos desde el reconocimiento y el respeto permite que se caigan por sí solos esos "muros de aire" ${ }^{15}$ construidos entre nosotras con base a prejuicios sociales que muchas veces reproducimos sin cuestionarlos ni ponerlos en duda.

En este sentido, las diferencias son una oportunidad para mover y sacudir nuestra caja de identidades; para poner en duda nuestros automatismos en el hacer y cuestionar nuestros pensamientos normativos. De poco sirve estar juntas si las diferencias no nos interpelan

\footnotetext{
15 "Muros de aire" es una metáfora muy gráfica que le escuché por primera vez a Haizea Miguela, compañera y amiga feminista, quien durante mi investigación me ayudó a ponerles nombre a muchos de los miedos y prácticas de desconfianza vividos dentro de la Plataforma de la Marcha Mundial de Mujeres.
} 
ni nos posibilitan cuestionarnos y abrirnos a lo diferente y a lo desconocido, no como una amenaza, sino como una oportunidad.

Además, poner en contacto nuestras diferencias, piel con piel, reduce esa distancia no solo física sino también relacional, emocional e ideológica y abre la posibilidad para la construcción conjunta de un espacio de intercambio donde las diferencias puedan dialogar y encontrarse, lo que no implica que se vayan a resolver. Como sostiene Audre Lorde (1984, p. 41) en su ponencia sobre la transformación del silencio en lenguaje y en acción: "No nos escondamos detrás de las falsas separaciones que nos han impuesto y que tan a menudo aceptamos como propias". Romper con la tiranía del silencio (Lorde, 1984) en la que hemos sido socializadas y atrevernos a hablar, aun a riesgo de ser rechazadas o de que nuestras palabras sean malentendidas, es imprescindible en la lucha hacia la radicalización del feminismo.

De acuerdo con la autora (1984): "Mis silencios no me han protegido. Tampoco las protegerán a ustedes [...]. Nuestra educación nos ha enseñado a tener mayor respeto al miedo que a nuestra propia necesidad de hablar y definirnos, y mientras aguardamos en silencio a que al fin se nos conceda el lujo de perder el miedo, el peso del silencio va ahogando" (pp. 41-44). Para la autora está claro: no son las diferencias las que nos inmovilizan, sino el silencio por miedo al desprecio, a la censura, a la condena o a los efectos que puedan tener nuestras palabras. Todavía existen entre nosotras una multitud de silencios que debemos comenzar a romper.

\section{Crear espacios emocionales de cuidado entre nosotras}

Una politica de diálogo y de escucha sincera requiere generar espacios donde las emociones también tengan cabida. En este sentido las articulaciones politicas implican también tejer articulaciones afectivas. No solo somos cuerpos racionales, también somos cuerpos emocionales que, además de pensar y actuar, sentimos. 
Cuando hablamos de emociones no solo nos referimos a las positivas, sino sobre todo a aquellas que solemos identificar como negativas, como es el caso de la rabia o del enfado. Estas emociones, debido a los mandatos de género, están más penalizadas en el caso de las mujeres. Por lo tanto, generar espacios donde sea posible expresar la rabia, el enfado o el dolor entre nosotras, desde el respeto y la escucha, es fundamental si queremos transformar nuestras relaciones de poder. Esto sigue siendo un reto en la Plataforma de la MME, pero hemos realizado algunos intentos que merecen ser examinados.

En primer lugar, producto de ciertos malestares que llevaban tiempo dándose entre nosotras debido a que algunos grupos no se sentían cómodos con las dinámicas de funcionamiento que se estaban generando a la hora de tomar decisiones, dinámicas que muchas veces pedian a los grupos respuestas rápidas y una implicación que no todos podian dar de la misma manera, decidimos realizar un taller de sentires ${ }^{16}$ donde compartir esos malestares que se respiraban en la atmósfera, pero que no acabábamos de exponer claramente. El taller de sentires, a pesar de ser una novedad para muchas, tuvo muy buena acogida, aunque finalmente no participamos todos los colectivos que estábamos entonces en el grupo dinamizador ${ }^{17}$.

Durante el taller dimos espacio para que cada una pudiera expresar cómo se sentía en el grupo dinamizador y qué significaba la Marcha, tanto a nivel individual como a nivel colectivo. Partimos del respeto a la hora de escucharnos, intentando que no saliera el juicio inmediato, y de brindar un espacio donde nos pudiéramos sentir libres para expresar nuestras emociones. Resultó una sorpresa para muchas escuchar a las compañeras que trabajan en el área de género dentro de sindicatos decir que el grupo dinamizador de la Marcha era para ellas un lugar de respiro, debido a que en el sindicato muchas veces para conseguir incidir y poner los temas de género tenían que estar constantemente en la pelea. En ese sentido, la Marcha era un

16 El taller de sentires se realizó en una jornada de mañana, el 9 de mayo del 2015, y fue dinamizado por la propia investigadora, quien recogió en un documento la síntesis del mismo.

17 Uno de los grupos que mostró malestar por las dinámicas y prácticas de funcionamiento y sugirió la posibilidad de tener un encuentro para compartir los diferentes sentires que había en la Marcha finalmente no participó y decidió salir del grupo dinamizador. 
espacio del cual sacaban fuerza para su lucha cotidiana. Otra compañera manifestó que en muy pocos espacios de articulación se había sentido cómoda y no juzgada por ser lesbiana, y que el grupo dinamizador era para ella un espacio emocional donde además se tejen relaciones afectivas y de amistad. Por otro lado, también hubo lugar para que compañeras expresaran la ansiedad que les generaba la rapidez con la que se tomaban las decisiones y el poco disfrute a nivel personal y colectivo que estaban viviendo del proceso. En esa misma línea, otra compañera manifestaba la inmensa energía y el desgaste que estaba suponiendo todo el cúmulo de actividades que requería organizar el paso de la caravana y el miedo a las consecuencias que podría generar ese desgaste en el futuro. Por tanto, la experiencia del taller de sentires fue un laboratorio que posibilitó expresar y compartir también nuestros agobios, malestares y preocupaciones para, desde ahí, poder pensar de manera colectiva posibles alternativas que los contrarresten.

Otra experiencia, en la que el enfado o más bien el dolor pudo ser expresado surgió a raíz de una exposición de fotos que realizamos una vez terminada la caravana. La exposición se organizó dentro de la jornada "alternatiben herria"18, que impulsaron diferentes colectivos y movimientos sociales. Resulta que nos ofrecieron un espacio para exponer fotos del paso de la Caravana feminista por Euskal Herria. La propuesta surgió cuando apenas faltaba una semana para el evento, lo que generó que se preparara de forma muy rápida y sin una participación de todas en la selección de las fotos. Una compañera afroecuatoriana que había participado en las actividades de la marcha se sintió muy dolida cuando al ir a ver las fotos de la exposición advirtió que no había ninguna en la que apareciera una mujer negra. Producto del dolor escribió una carta donde exponía los argumentos por los que se había sentido excluida y discriminada y cómo la exposición no reflejaba la diversidad que se había vivido en la Marcha. Tras leer la carta en una reunión del grupo dinamizador, la mayoría de las compañeras de los diferentes grupos no reaccionó de forma defensiva ni eludiendo su responsabilidad, sino más bien reconociendo cómo muchas veces al ocupar posiciones normativas reproducimos las lógicas coloniales

18 Alternatiben herria, o alternativa de los pueblos en castellano, fue una iniciativa que se celebró el 24 de octubre en Bilbao con motivo de la Cumbre sobre el Cambio Climático, que tuvo como objetivo mostrar los proyectos y alternativas anticapitalistas que se están llevando a cabo en Euskal Herria. 
heredadas. "Estas inercias coloniales que muchas veces reproducimos de manera inconsciente", como manifestaba una compañera (Diario de campo, comunicación personal, 29 de octubre del 2015), las tenemos muy incorporadas y es a través de la interpelación de las otras cuando podemos ser conscientes de ellas.

Para ello es imprescindible crear espacios afectivos y de cuidado entre nosotras donde tenga cabida la posibilidad de equivocarnos, de "meter la pata", de reconocer prácticas patriarcales y coloniales ente nosotras, de atrevernos a ser sinceras desde el respeto, sabiendo que es un proceso de construcción colectiva en el que todas vamos aprendiendo en el hacer y en la práctica.

Como sostiene la feminista chicana Cherrie Moraga (Moraga y Castillo, 1988) las mujeres tenemos aún el reto de reconocer la opresora que llevamos dentro, "pues cada una ha sido en alguna medida oprimida y opresora. Tenemos que ver cómo nos hemos fallado una a la otra. Tenemos miedo de cómo hemos incorporado los valores de nuestro opresor en nuestros corazones, volteándonos contra nosotras mismas y contra otras. Tenemos miedo de admitir lo mucho que del mundo 'del hombre' hemos integrado dentro de nosotras mismas" (pp. 25-26).

Por último, esta apertura a acercarnos desde lo emocional, ha permitido bajar las posiciones de defensa, autoexclusión y desconfianza entre nosotras, bajo discursos totalizadores como "siempre al final nos marginan "o "es imposible, nunca nos verán igual" y posiciones excluyentes y dicotómicas "ellas"/"nosotras", que redifican las posiciones fijas, conocidas y habituales que son finalmente más cómodas que abrirse a lo desconocido, a la incertidumbre e inseguridad que provoca la apertura a transformar y dejarse transformar.

En este sentido, para Cherrie Moraga y Ana Castillo (1988), lo afectivo se vuelve un elemento crucial de toda práctica política. Es desde la práctica y no desde la teoria; desde el propio reconocimiento de las diferencias y de las contradicciones que albergamos al interior y 
que nos constituyen, como podemos llegar a conectar con la situación de opresión de las otras. Para las autoras (p. 21):

el peligro radica en tratar de enfrentar las opresiones en términos meramente teóricos. El peligro radica en no ser capaz de reconocer la especificidad de cada opresión. Sin una envoltura emocional sentida en el corazón que surja de nuestra opresión, sin que se nombre al enemigo que llevamos dentro de nosotras mismas y fuera de nosotras, ningún contacto auténtico no jerárquico entre grupos oprimidos puede llevarse a cabo.

\section{Conclusiones inacabadas}

A partir de la experiencia de la plataforma de la MME me gustaria poder terminar con algunas reflexiones finales que abran nuevas perspectivas para la construcción de espacios de articulación feminista desde y a través de las diferencias.

En primer lugar, se torna clave tejer articulaciones plurales y permeables a las diferentes formas de luchas y resistencia; espacios porosos que se dejen contaminar por distintas maneras de reivindicar y sentir la política. Estar disponibles a la apertura implica no solo quedarse en la enumeración de nuestras diferencias, sino develar sus origenes y efectos materiales, reconociendo las desiguales condiciones de vida y acceso a recursos y derechos que existen entre nosotras. Superar la retórica de las diferencias conlleva concebir la igualdad sin negar las diferencias, comprendiendo la igualdad como un territorio compuesto por diversidades no homologables entre ellas y a la vez irreductibles en su singularidad.

En segundo lugar, es imprescindible tener en cuenta que el racismo sigue existiendo más allá de la solidaridad entre mujeres (Lorde, 1984). Por ello, articular la lucha feminista y antirracista implica analizar la construcción de la femineidad blanca y explorar cómo el género de las mujeres blancas también se construye a través de la clase y el 
racismo. En este sentido, la presencia activa de las mujeres migradas es fundamental para interpelar a las feministas vascas sobre sus actitudes racistas.

En tercer lugar, urge una nueva ética del reconocimiento que tenga como epicentro las diferencias. Esto conlleva generar nuevas prácticas que rompan con la tiranía del silencio (Lorde, 1984) y apuesten por la política del diálogo y la escucha, en las que las diferencias puedan ser un motor para el desplazamiento de nuestras identidades y para la ruptura de prácticas patriarcales y coloniales entre nosotras. Para ello, se torna clave generar y potenciar espacios de encuentro entre nosotras, espacios políticos - emocionales, como los he denominado, que nos permitan acercarnos, conocernos y afectarnos unas a otras, para romper a través del contacto esas barreras y muros que el heteropatriarcado ha reforzado históricamente entre mujeres.

En definitiva, se trata de crear articulaciones no tanto desde la unidad del "todas estamos oprimidas" o desde una suma de identidades prefijadas, sino desde la construcción de "un común" no totalizante, que parta de las situaciones vitales y políticas específicas de los sujetos. Como señala Silvia L. Gil (2014, p. 51), "este punto de arranque no supone renunciar a la universalidad de la emancipación, sino comprenderla encarnada en procesos concretos"; es decir, que el hilo articulador sean las diversas experiencias vitales de los sujetos que conformamos la Plataforma de la MME. El reto, por tanto, es construir lugares comunes que expresen situaciones compartidas, sin negar las diferencias y sin abandonar la complejidad, la singularidad y la multiplicidad existentes. Desde esta mirada, la pregunta a resolver no es tanto quiénes somos, sino más bien en qué queremos convertirnos. Es desde esa proyección común que podemos impulsarnos hacia una práctica de articulaciones feministas no espontáneas ni naturales, sino construidas y en constante revisión y aprendizaje.

Por último, y para acabar, este proceso de articulación presentado tiene más preguntas y dudas que certezas: ¿Cómo materializar en la práctica las experiencias de desigualdad que nos atraviesan y a su vez reivindicar una politica de articulación no identitaria? Los interrogantes, 
las incertidumbres y las contradicciones están siendo un continuo aprendizaje en el reto de construir articulaciones feministas que apuesten por la reconfiguración de las diferencias y la creación de nuevos sentidos comunes.

\section{Referencias}

Álvarez, S. E. (1998). Feminismos latinoamericanos. Estudios feministas, 6(2), 265-284.

Anthias, F. (2002). Beyond feminism and multiculturalism: Locating difference and the politics of location. Women's Studies International Forum, 25(3), 275286.

Biglia, B. (2007). Desde la investigación-acción hacia la investigación activista feminista. En Perspectivas y retrospectivas de la Psicología Social en los albores del siglo XXI (pp. 415-422). Madrid: Biblioteca Nueva.

Bouteldja, H. (2010, octubre), ¿Es el feminismo universal? Intervención realizada en el IV Congreso Internacional de Feminismo Islámico. Red Musulmanas. Madrid, España. Recuperado de http://www.redmusulmanas.com/houriabouteldja-portavoz-del-pir-en-el-el-iv-congreso-internacional-de-feminismoislamico

Brah, A. (1996/2011). Cartografias de la diáspora. Identidades en cuestión. Madrid: Traficantes de Sueños.

Braidotti, R. (1992). The exile, the nomad, and the migrant: reflections on international feminism. Women's Studies International Forum, 15(1),7-10.

Butler, J. (2001). El género en disputa. México: Paidós.

Butler, J. (2009). Marcos de guerra. Vidas lloradas. Barcelona: Paidós.

Davis, A. Y. (1981). Women, Race, and Class. New York: Vintage. 
De Lauretis, T. (1992). Alicia ya no: feminismo, semiótica, cine (Vol. 9). València: Universitat de València.

De Roure, S. (2010). Cambiar la vida para cambiar el mundo. La experiencia de la Marcha Mundial de las Mujeres. Fundación Betiko. Recuperado de http:// fundacionbetiko.org/wp-content/uploads/2012/11/cambiar-la-vida-de-lasmujeres-para-cambiar-el-mundo-la-experiencia-de-la-marcha-mundial-deas-mujeres.pdf

Espinosa-Miñoso, Y. (2014). Una crítica descolonial a la epistemología feminista crítica. Revista El cotidiano. Género: visiones y debates necesarios, 7-12.

Faria, N. (2005). Marcha Mundial de las Mujeres: un movimiento irreversible. Mujeres en red. Recuperado de http:/ /www.mujeresenred.net/spip.php?article666

Femenías, M. L. (2012). Igualdad y diferencia: dos niveles de análisis. Cuadernos Kóre, 1(5), 9-43.

Fraser, N. (2008). La justicia social en la era de la politica de identidad: redistribución, reconocimiento y participación. Revista de trabajo, 4(6), 83-99.

Fuss, D. (2013). Essentially speaking: Feminism, nature and difference. New York: Routledge.

Gandarias, I. y Pujol, J. (2013). De las otras al no(s)otras: encuentros, tensiones y retos en el tejido de articulaciones entre colectivos de mujeres migradas y feministas locales en el País Vasco. Encrucijadas: Revista Crítica de Ciencias Sociales, 5, 77-91.

Garcés, M. (2013). Un mundo común. Barcelona: Bellaterra.

Gil, S. L. (2014). Debates en la teoría feminista contemporánea: sujeto, ética y vida común. Quaderns de Psicologia, 16(1), 45-53.

Gil, S. L. (2015). Nuevas politizaciones para nuevos corazones. Hacia una politica de lo común. México: Tercera Vía. 
Grewal, I. y Kaplan, C. (Eds.). (1994). Scattered hegemonies: Postmodernity and transnational feminist practices. Minneapolis: University of Minnesota Press.

Hall, S. (2003). Introducción: ¿quién necesita identidad. En S. Hall y P. Du Gay, Cuestiones de identidad cultural (pp. 13-41). Buenos Aires: Amorrortu.

Hernández Castillo, R. A. (2003). Posmodernismos y feminismos: diálogos, coincidencias y resistencias. Desacatos, 13, 107-121.

Hooks, B. (1981). Ain't I a Woman. Black Women and Feminism. Boston (MA): South End.

Juliano, D. (2014). Entrevista a Dolores Juliano. Periódico Diagonal. Recuperado de https://www.diagonalperiodico.net/saberes/25296-se-nos-olvida-haysectores-mujeres-con-necesidades-y-problemas-especificos.html

Lorde, A. (1982). Zami, A new spelling of my name. New York: Random House Digital, Inc.

Lorde, A. (1984). Sister outsider: Essays and speeches. Berkeley, California: Crossing Press.

Lugones, M. (2008). "Colonialidad y género: Hacia un feminismo descolonial". En W. Mignolo (Comp.), Género y descolonialidad (pp. 13-54). Buenos Aires: Ediciones del Signo.

Mendoza, B. (2002). Transnational Feminisms in Question. Feminist Theory, 3(3), 295-314.

Minow, M. (1985). Learning to live with the dilemma of difference: Bilingual and special education. Law and Contemporary Problems, 157-211.

Mohanty, C.T. (2003). Under Western Eyes Revisited: Feminist Solidarity through Anticapitalist Struggles. Signs: Journal of Women in Culture and Society, 28(2), 499-535. 
Moraga, C. y Anzaldúa, G. (Eds.). (1981). This bridge called my back: Writings by radical women of color. New York: SUNY Press.

Moraga, C. y Castillo, A. (1988). Esta puente, mi espalda: voces de mujeres tercermundistas en los Estados Unidos. San Francisco: Ism Press.

Nash, J. C. (2008). Re-thinking intersectionality. Feminist review, 89(1), 1-15.

Nnaemeka, O. (2008). Conferencias Internacionales como Escenarios para la Lucha Feminista Transnacional: el caso de la Primera Conferencia Internacional sobre las Mujeres de África y de la Diáspora Africana. En S. Marcos y M. Waller (Eds.), Diálogo y Diferencia. Retos feministas a la globalización (pp. 81-101). México: Centro de Investigaciones Interdisciplinarias en Ciencias y Humanidades de la Universidad Nacional Autónoma de México.

Pérez Orozco, A. (2012). Crisis multidimensional y sostenibilidad de la vida. Investigaciones feministas, 2, 29-53.

Restrepo, E. (2006). Identidades: planteamientos teóricos y sugerencias metodológicas para su estudio. Jangwa Pana, 5(1), 24-35.

Woolf, V. (1929/1995). Una habitación propia. Barcelona: Seix Barral.

\section{Cómo citar este artículo}

Gandarias Goikoetxea, I. (2017). De la unidad a lo común: hacia una articulación feminista de las diferencias. La experiencia de la Plataforma de la Marcha Mundial de Mujeres de Euskal Herria. Universitas Humanística, 83, 361-387. http:/ /dx.doi.org/10.11144/Javeriana.uh83.ucaf 